\title{
HUBUNGAN TINGKAT STRES DAN KARAKTERISTIK REMAJA PUTRI DENGAN KEJADIAN DISMENORE PRIMER
}

\section{CERRELATION OF STRESS LEVELS AND CHARACTERISTICS OF TEENAGE GIRL WITH THE PRIMARY DISMENORE INCIDENCE}

\author{
Sri Rejeki ${ }^{1}$, Nikmatul Khavati ${ }^{2}$, Riski Yunitasari ${ }^{3}$ \\ ${ }^{1}$ Praktisi dan dosen Keperawatan Maternitas FIKKES UNIMUS \\ ${ }^{2}$ Praktisi keperawatan UNIMUS \\ ${ }^{3}$ Praktisi Keperawatan \\ Email : srirejeki@unimus.ac.id
}

\begin{abstract}
ABSTRAK
Dismenore merupakan nyeri yang muncul saat terjadinya mentruasi pada perempuan. Yang dapat disarakan sebagai gangguan aktivitas sehari-hari. Dismenorhea dapat dipengaruhi dengan adanya aktivitas fisik, kondisi psikologis yang tidak adekuat serta beberapa konsisi lain seperti karakteristik seseorang yang sedang mangalami menstruasi. Penelitian ini bertujuan untuk menggambarkan tingkat stress dan karakteristik dihungkan dengan kejadfian dismenorhea pada remaja putri di SMP N 3 Pekalongan. Metode penelitian berupa survey dengan pedekatan cross sectional. Sebanyak 61 remaja putri yang diambil secara total terlibat dalam penelitian ini. Hasil penelitian didapatkan $89 \%$ remaja putri mengalami strss sedang dan ada hubungan tingkat stress remaja putri dengan Dismenorhea dengan nilai Pvalue $=0,006(P<0.05)$.
\end{abstract}

Kata kunci $\quad$ :Dismenore, Karakteristik, tingkat Stress

\section{ABSTRACT}

Dysmenorrhea is pain that occurs when menstruation occurs in women. Which can be suggested as a disruption of daily activities. Dismenorrhea can be affected by physical activity, inadequate psychological conditions and several other conditions such as the characteristics of someone who is experiencing menstruation. This study aims to describe the level of stress and characteristics correlated with the incidence of dysmenorrhea in young women in Public Junior High School 3 Pekalongan. The research method is a survey with cross sectional approach. A total of 61 teenage girl who were taken were totally involved in this study. The results showed $89 \%$ of teenage girl had moderate stress and there was a correlation between stress levels of teenage girl with dysmenorrhea with a value of $p$ value $=0.006(P<0.05)$.

Keyword : Dysmenorrhea, Characteristics, Stress Level

\section{PENDAHULUAN}

Dismenorhea merupakan masalah yang terjadi pada saat perempuan mengalami mestruasi. Dismenore merupakan nyeri menstruasi yang dikarakteristikan sebagai nyeri singkat sebelum awitan atau selama menstruasi yang merupakan permasalahan ginekologikal utama, yang sering dikeluhkan oleh perempuan (Lowdermilk, Perry, \& Cashion, 2011). Menurut Hendrik (2006). Faktor penyebab terjadinya dismenore yaitu keadaan psikis dan fisik yang terganggu seperti stres, shock, penyempitan pembuluh darah, dan kondisi tubuh yang menurun (Diyan, 2013). Pendidikan, faktor psikis seperti stress,dan kesehatan yang rendah seperti anemia dapat memperburuk keadaan dismenorea (Icesma, 2013).

Perbedaan faktor penyebab dapat menimbulkan karakteristik yang berbeda pada saat dismenore. Dari hal tersebut maka dismenore dapat dikategorikan menjadi 2 yaitu dismenore primer dan sekunder. Dismenore primer yaitu suatu kondisi yang dihubungkan dengan siklus 
ovulasi, sedangkan dismenore sekunder merupakan nyeri menstruasi yang berkembang dari dismenore primer yang terjadi sesudah usia 25 tahun dan penyebabnya karena kelainan pelvis (Lowdermilk, Perry, \& Cashion, 2011).

Pada dismenore primer biasanya terjadi pada seorang wanita yang mengalami menarche setelah 2-3 tahun dan bisa mencapai umur 15-25 tahun. Frekuensi akan menurun dengan bertambahnya usia dan akan berhentisetelah melahirkan. Adanya suatu penonjolan pada aktivasi kinerja protaglandin $\mathrm{F}_{2 \mathrm{a}}$ yang timbul akibat gangguan keseimbangan antara prostaglandin-prostaglandin $\mathrm{E}_{2}$ dan $\mathrm{F}_{2 \mathrm{a}}$ dengan prostasiklin, yang disintesis oleh sel-sel endometrium uteri (Hendrik, 2006). Peningkatan produksi prostaglandin dan pelepasannya (terutama $\mathrm{PGF}_{2 \mathrm{a}}$ ) dari endometrium selama menstruasi menyebabkan kontraksi uterus yang tidak terkoordinasi dan tidak teratur sehingga timbul nyeri (Reeder. 2013). Adapun Tanda gejala dari dismenore primer yaitu nyeri pada daerah pinggang, mualdanmuntah, sakitkepala, letih, pusing, pingsan, dandiare, serta kelabilan emosi selama menstruasi (Reeder, 2013).

Penelitian ini bertujuan mendeskripsikan hubungan karakteristik remaja serta tingkat stress dengan kejadian dismenorhea.

\section{METODE PENELITIAN}

Penelitian ini menggunakan metode survey dengan pendekatan cross sectional. Populasi dalam penelitian semua siswi SMP N3 Pekalongan. Sebanyak 61 remaja putri dengan dismenorrea diambil secara total. Alat pengumpulan data dengan lembar kuesioner yang diberikan secara bersamaan. Data dianalisis secara univariat dan bivariat dengan Rank Spearman.

\section{HASIL DAN PEMBAHASAN}

Hasil penelitian diperoleh rata-rata umur 14,3038 tahun, mayoritas usia menarche responden 12 tahun, dengan $93,4 \%$ orang tua responden masih ada semua. Pada penelitian ini mayoritas siswi anak pertama dan anak kandung, 93,4 \% tinggal bersama orang tua dengan jarak rumah kesekolah terbanyak $1 \mathrm{~km}$. Diperoleh hasil tidak ada hubungan antara karakteristik umur dengan kejadian dismenore primer. Tidak ada hubungan antara karakteristik usia menarche dengan kejadian dismenore primer. Dan ada hubungan antara tingkat stres dengan kejadian dismenore primer.

Tabel 1

Distribusi Frekuensi Berdasarkan Umur Responden

Tahun 2017 (N: 61)

\begin{tabular}{lrr}
\hline Umur & Frekuensi (f) & Persentase (\%) \\
& & \\
\hline 13 & 23 & 37,8 \\
14 & 29 & 47,5 \\
15 & 7 & 11,5 \\
16 & 1 & 1,6 \\
17 & 1 & 1,6 \\
\hline Total (N) & 61 & 100,0 \\
\hline
\end{tabular}

Mean umur: 12 tahun

Tabel 2

Distribusi Frekuensi Berdasarkan Usia Menarche Responden

Tahun 2017 (N: 61)

\begin{tabular}{lrr}
\hline $\begin{array}{l}\text { Usia } \\
\text { Menarche }\end{array}$ & $\begin{array}{r}\text { Frekuensi } \\
(\mathrm{f})\end{array}$ & $\begin{array}{r}\text { Persentase } \\
(\%)\end{array}$ \\
\hline 10 Tahun & 3 & 4,9 \\
11 Tahun & 11 & 18,0 \\
12 Tahun & 25 & 41,0 \\
13 Tahun & 18 & 29,5 \\
14 Tahun & 4 & 6,6 \\
& & \\
\hline Total $(\mathrm{N})$ & 61 & 100,0 \\
\hline
\end{tabular}


Tabel 3

Distribusi Frekuensi Berdasarkan Anak ke Berapa Responden

Tahun 2017 (N: 61)

\begin{tabular}{lrr}
\hline $\begin{array}{l}\text { Anak } \\
\text { Ke }\end{array}$ & Frekuensi (f) & Persentase (\%) \\
\hline 1 & & 37,7 \\
2 & 23 & 24,6 \\
3 & 15 & 16,4 \\
4 & 10 & 14,8 \\
5 & 9 & 6,6 \\
\hline Total & 4 & 100,0
\end{tabular}

(N)

Tabel 4

Distribusi Frekuensi Berdasarkan Status

Responden

Tahun 2017 (N: 61)

\begin{tabular}{lrr}
\hline Status & Frekuensi (f) & Persentase (\%) \\
\hline Anak & 60 & 98,4 \\
kandung & 1 & 1,6 \\
Bukan Anak & & \\
Kandung & & 100,0 \\
\hline Total (N) & 61 & \\
\hline
\end{tabular}

Tabel 5

Distribusi Frekuensi Berdasarkan Jarak Rumah ke Sekolah Responden

Tahun 2017 (N: 61)

\begin{tabular}{lrr}
\hline Jarak & Frekuensi (f) & Persentase (\%) \\
\hline $1 \mathrm{~km}$ & 47 & 77,0 \\
$2 \mathrm{~km}$ & 11 & 18,0 \\
$3 \mathrm{~km}$ & 3 & 5,0
\end{tabular}

\begin{tabular}{lll}
\hline $\operatorname{Total}(\mathrm{N})$ & 61 & 100,0 \\
\hline
\end{tabular}

Tabel 6

Distribusi Frekuensi Berdasarkan Tingkat Stres Responden

Tahun 2017 (N: 61)

\begin{tabular}{lcr}
\hline $\begin{array}{l}\text { Tingkat } \\
\text { Stres }\end{array}$ & Frekuensi (f) & Persentase (\%) \\
\hline Ringan & 20 & 32,8 \\
Sedang & 41 & 67,2 \\
\hline Total (N) & 61 & 100,0 \\
\hline
\end{tabular}

Tabel 7

Distribusi Frekuensi Berdasarkan Kejadian Dismenore Primer Responden

Tahun 2017 (N: 61)

\begin{tabular}{crr}
\hline Dismenore & Frekuensi (f) & Persentase (\%) \\
\hline Ya & 42 & 68,9 \\
Tidak & 19 & 31,1 \\
\hline Total (N) & 61 & 100,0 \\
\hline
\end{tabular}

Tabel 8

Hubungan Karakteristik Umur dengan Kejadian Dismenore Primer Siswi SMP N 3 Pekalongan

Tahun 2017 (N: 61)

\begin{tabular}{llll}
\hline Variabel & $\mathrm{N}$ & $\mathrm{R}$ & $\mathrm{p}$ \\
\hline Hubungan & 61 & $-0,102$ & 0,436 \\
karakteristik & & & \\
umur dengan & & & \\
kejadian & & & \\
dismenore & & & \\
primer & & & \\
\hline
\end{tabular}

Tabel 9

Hubunngan Karakteristik Usia Menarche dengan Kejadian Dismenore Primer Siswi SMP N 3 Sragi Tahun 2017 (N: 48)

\begin{tabular}{llll}
\hline Variabel & $\mathrm{N}$ & $\mathrm{R}$ & $\mathrm{p}$ \\
\hline Hubungan & 61 & 0,151 & 0,247 \\
karakteristik usia & & & \\
menarche dengan & & & \\
kejadian dismenore & & & \\
primer & & & \\
\hline
\end{tabular}

Tabel 10

Hubungan tingkat stres dengan Kejadian Dismenore Primer Siswi SMP N 3 Sragi Tahun 2017 (N:61)

\begin{tabular}{lccc}
\hline Variabel & $\mathrm{N}$ & $\mathrm{R}$ & $\mathrm{p}$ \\
\hline Hubungan tingkat stres dengan & 6 & - & 0, \\
Kejadian Dismenore Primer & 1 & 0,3 & 00 \\
& & 45 & 6 \\
\hline
\end{tabular}

Hasil penelitian ini didapatkan koefisien korelasi sebesar -0,102 dengan nilai $\mathrm{P}$ sebesar 0,436 $(\mathrm{P}>0,05)$, sehingga dapat dinyatakan tidak terdapat hubungan antara karakteristik umur dengan kejadian dismenore primer. Hasil penelitian ini tidak sejalan dengan penelitian Novia \& Puspitasari (2011), bahwa umur memengaruhi kejadian dismenore, 
kemudian dikatakan bahwa responden yang berumur 15-25 tahun mempunyai risiko 0,013 kali lebih sering terkena dismenore primer dibandingkan dengan responden yang berumur 26-30 tahun. Penelitian ini juga berbeda dengan teori yang dikatakan oleh French (2005) dalam Hasanah (2010) dismenore dipengaruhi oleh usia menarche yang terlalu dini dan usia kurang dari 20 tahun. Hal ini disebabkan karena usia responden ada yang di bawah 15 tahun.

Berdasarkan hasil penelitian ini dengan menggunakan uji korelasi Rank Spearman didapatkan koefisien korelasi sebesar 0,151 dengan nilai P sebesar 0,247 $(\mathrm{P}>0,05)$, sehingga dapat dinyatakan tidak terdapat hubungan antara karakteristik usia menarche dengan kejadian dismenore primer.Menurut hasil penelitian Wahyu \& Rahmayani (2013) pada mahasiswi di Akademik Kebidanan Meuligo Meulaboh setelah dilakukan uji statistik diperoleh hasil nilai Pvalue $=0,047$, yaitu terdapat pengaruh antara umur menarche dengan kejadian dismenore. Sedangkan penelitian yang di lakukan oleh Gustina (2015) tidak ada hubungan antara usia menarche dengan kejadian dismenore primer pada remaja putri di SMK N 4 Surakarta, dan tidak ada hubungan antara lama menstruasi dengan kejadian dismenore primer, dengan nilai $\mathrm{Pvalue}=0,783>0,05$.

Pada penelitian ini karakteristik usia menarche responden yang mengalami dismenore tidak mempunyai hubungan dengan kejadian dismenore primer sesuai dengan penelitian Gustina (2015) mayoritas siswi menarche pada usia 13 tahun, berbeda dengan pendapat Alulkumaran (2006) dalam Priyanti (2014) bahwa menarche dini dan siklus menstruasi yang panjang menyebabkan dismenore. Mayoritas siswi menarche berusia 12 tahun, dan terbanyak kedua berusia 13 tahun, hal inilah yang menyebabkan sama dengan penelitian Gustina.

Usia menarche yang terlalu dini, dimana organ-organ reproduksi belum berkembang secara maksimal dan masih terjadi penyempitan pada leher rahim, maka akan timbul rasa sakit pada saat menstruasi. Wanita yang memiliki usia menarche dini yang berisiko, harus memperhatikan masalah kesehatannya terutama akan kejadian dismenore (Proverawati \& Misaroh, 2009).

Hasil penelitian dengan menggunakan uji korelasi Rank Spearman didapatkan koefisien korelasi sebesar 0,345 dengan nilai $\mathrm{P}$ sebesar $0,006(\mathrm{P}<$ $0,05)$. Sehingga dapat dinyatakan terdapat hubungan yang signifikan antara tingkat stres dengan kejadian dismenore primer.Hasil penelitian ini menunjukkan bahwa tingkat stres siswi dapat memperburuk kejadian dismenore primer pada siswi kelas VIII SMP N 3 Sragi.

Menurut hasil penelitian Priyanti \& Mustikasari (2014) pada remaja putri di Madrasah Aliyah Mamba'ul Ulum Awangawang Mojosarididapatkannilai Pvalue= $0,02(\mathrm{P}<0,05)$ yaitu ada hubungan tingkat stres dengan terjadinya dismenore pada remaja putri di Madrasah Aliyah Mamba'ul Ulum Awang-awang Mojosari kabupaten Mojokerto. Selanjutnya penelitian yang dilakukan oleh Sari (2013) terdapat hubungan yang bermakna dengan korelasi sedang antara tingkat stress dengan derajat dismenore primer. Sedangkan pada penelitian Ismail (2015) tidak terdapat hubungan yang berarti antara tingkat stres dengan kejadian dismenore.

Tingkat stres pada siswi kelas VIII SMP N 3 Pekalongan yaitu stres ringan $(10,4 \%)$ dan stres sedang $(89,6 \%)$. Penelitian ini sejalan dengan penelitian yang dilakukan Bekti (2014) dimana sebagian besar siswi SMK mengalami stres sedang $(47,8 \%)$.

Dalam penelitian ini tidak terdapat responden yang mengalami stres berat, hal ini didukung oleh penelitian, siswi selalu terbuka dengan teman sebaya. Sehingga mereka tidak merasa sangat terbebani ketika mempunyai masalah.

Pada saat stres, melalui saraf indra stresor akan diteruskan ke bagian saraf 
otak yang disebut lymbic system (neurotransmitter), selanjutnya stimulus akan diteruskan ke kelenjar-kelenjar hormonal (endokrin) yang merupakan sistem imunitas tubuh dan organ-organ tubuh yang dipersyarafinya. Stimulus tadi akan mengakibatkan produksi hormon adrenalin meningkat kemudian masuk ke peredaran darah dan mempengaruhi jantung (berdebar-debar), tekanan darah meninggi, asam lambung meningkat, emosi tidak terkendali, dan lain sebagainya. Gangguan pada sistem endokrin yang mngalami stres berupa gangguan menstruasi yang tidak teratur dan dismenore (Hawari, 2011). Selanjutnya menurut Handrawan (2008) pada saat stres, tubuh akan memproduksi hormon adrenalin, estrogen, progesteron serta prostaglandin yang berlebihan. Estrogen dapat meningkatkan kontraksi uterus. Meningkatnya hormon adrenalin juga menimbulkan otot tubuh tegang termasuk otot rahim yang berakibat pada penurunan perfusi ke jaringan endometrium, sehingga pembuluh darah terjepit oleh otot uterus yang menyebabkan suplai oksigen berkurang dan menjadi iskemik.

\section{SIMPULAN}

Tidak ada hubungan antara karakteristik umur responden dengan kejadian dismenore primer pada remaja putri SMP N 3 pekalongan dengan nilai $p$ sebesar 0,436. Tidak ada hubungan antara karakteristik usia menarche dengan kejadian dismenore primer pada remaja putri SMP N 3 Pekalongan dengan nilai $p$ sebesar 0,247.Terdapat hubungan yang bermakna antara tingkat stres dengan kejadian dismenore primer pada remaja putri SMP N 3 pekalongan dengan nilai $p$ sebesar 0,006 .

\section{DAFTAR PUSTAKA}

Bekti, Y., Masini., Hidayah, H.S.S. (2014). Hubungan Tingkat Stres dengan Tingkat Dysmenorrhoea pada Siswi
Kelas X dan XI SMK Bakhti Karyakota Magelang Tahun 2014.

Dian, S., Adnil, E.N., \& Defrin. (2013).

Hubungan Stres dengan Kejadian

Dismenore Primer Pada Mahasiswi

Pendidikan Dokter Fakultas

Kedokteran Universitas Andalas. Jurnal Kesehatan Andalas. 2015; 4(2), 567-570.

Diyan, Indriyani. (2013). Keperawatan Maternitas Pada Area Perawatan Antenatal. Yogyakarta: Graha Ilmu

Gustina, Tina. (2015). Hubungan Antara Usia Menarche dan Lama Menstruasi dengan Kejadian Dismenore Primer Pada Remaja Putri di SMK N 4 Surakarta. Universitas Muhammadiyah Surakarta 2015.

http://eprints.ums.ac.id/38652/17/N ASKAH\%20PUBLIKASI.oke.tina. pdf..Diunduh 12 Maret 2017

Hasanah, O. (2010). Efektivitas Terapi Akupresure Terhadap Dismenore Pada Remaja di SMPN 5 Dan SMPN 13 Pekanbaru. FIK UI.http://repository.unri.ac.id/xmlui /bitstream/handle/123456789/7455/ Artikel\%20Oswati.pdf? sequence $=$. Diunduh 11 Maret 2017

Hawari, D. (2011). Manajemen Stres Cemas dan Depresi. Jakarta: Balai Penerbit FKUI.

Hegazi, M \& Hassan N. (2007). Heart Rate Variabelity (HRV) In Young Healthy Females with Primary Dysmenorrhea. Bull Alex: Fac Med.

Hendrik. (2006). Problema Haid Tinjauan Syariat Islam dan Medis. Solo: Tiga Serangkai.

Hudson, T. (2007). Using Nutrition to Relieve Primary Dysmenorrheaa Alternative \& Complementary Therapies. Mary Ann Liebert, 125128.

Icesma Sukarni K-Margareth ZH. (2013). Kehamilan, Persalinan dan Nifas. Yogyakarta: Nuhamedika. 
Indria F, Rina K, \&Jill L. (2015). Hubungan Tingkat Stres dengan Kejadian Dismenorea pada Mahasiswi Semester VIII Program Studi Ilmu Keperawatan Fakultas Kedokteran Universitas SAM Ratulangi Manado.

Lowdermilk, Perry, \& Cashion. (2011). Maternity Nursing. Universitas Michigan: Mosby.

Ningsih, A. K. (2011). Hubungan Pengetahuan Dismenore Dengan Ketepatan Penanganan Dismenore Pada Siswi SMA Negri 1 Sragi Pekalongan. Stikes Ngudi Waluyo.http://perpusnwu.web.id/ka ryailmiah/documents/4516.pdf.Diu nduh 10 Oktober 2016

Novia, Ika \& Nunik P. (2011). Faktor Risiko yang Mempengaruhi Kejadian Dismenore Primer. 98.https://media.neliti.com/media/p ublications/3893-ID-faktor-risikoyang-mempengaruhi-kejadiandismenore-primer.pdf. Diunduh 14 Oktober 2016

Proverawati, A., \& Siti Misaroh. (2009). Menarche Menstruasi Penuh Makna. Yogyakarta: Nuha Medika.

Reeder, Martin, \& Koniak-Griffin. (2013). Keperawatan Maternitas Kesehatan Wanita, Bayi \& Keluarga Edisi 8 Vol 1. Jakarta: EGC.

Priyanti, S \& Anggraeni D. M. (2014). Hubungan Tingkat Stres terhadap Dismenore pada Remaja Putri di Madrasah Aliyah Mamba'ulum Ulum Awang-awang Mojosari Mojokerto.

Wahyu, F \& Rahmayani. (2013). FaktorFaktor yang Mempengaruhi Kejadian Dismenore Pada Mahasiswi di Akademik Kebidanan Meuligo Meulaboh Tahun 2013. http://simtakp.uui.ac.id/dockti/WA HYU_FITRIANA-

skripsi_ka_ayu_(pdf).pdf. Diunduh 20 Oktober 2016.
Yu Ting Chang, \& Yueh Chih Chen. (2009). Study of Menstrual Attitudes and Distress Among Posymenarcheal Femal Students in Hualien Country Journal of Nursing Research.

Zukri, ShamsunarnieMohd. (2009). Primary Dysmenorrhea among Medical and Dental University Students in Kelantan. Prevalence anda Associated Factors. International Medical J 